\author{
Anna WIEPRZKOWICZ1 \\ Dariusz HEIM ${ }^{2}$
}

\title{
WSPÓŁCZYNNIK TŁUMIENIA AMPLITUDY WAHAŃ TEMPERATURY IZOLACJI TERMICZNEJ MODYFIKOWANEJ MATERIAŁEM FAZOWO ZMIENNYM
}

\begin{abstract}
Celem artykułu jest wyznaczenie stabilności termicznej komponentu izolacyjnego modyfikowanego warstwą MFZ. Analiza została przeprowadzona w stanie niestacjonarnym na podstawie rozkładu temperatury w przekroju ściany. Zaprezentowane zostały wyniki obliczeń przeprowadzonych dla dwóch wprowadzonych przez autorów, zmodyfikowanych współczynników tłumienia (ZWT i ZWWT), pozwalających w pełni określić efekt zastosowania warstwy MFZ na stabilizację termiczną przegrody zewnętrznej. Współczynniki określono na podstawie analiz symulacyjnych w Polskich warunkach klimatycznych. Porównanie wyników uzyskanych dla przegrody referencyjnej oraz modyfikowanej warstwą MFZ pokazuje różnice $\mathrm{w}$ wartościach ZWT od kilku do kilkunastu procent zależności od analizowanego dnia wybranego okresu czasu.
\end{abstract}

Słowa kluczowe: dynamika cieplna, symulacja komputerowa, ściana zewnętrzna, sezon ogrzewczy, budynek zero-energetyczny

\section{Wprowadzenie}

Głównym zadaniem przegród zewnętrznych budynku jest utrzymanie stabilnych warunków cieplnych wewnątrz pomieszczeń, podczas gdy parametry środowiska zewnętrznego zmieniają się w sposób dynamiczny i nieregularny. Podstawowym parametrem determinującym strumień ciepła przenikającego przez warstwę materiału jest współczynnik przewodzenia ciepła, pozwalający określić jej oporność cieplną. Niemniej jednak, nie uwzględnia on bezwładności cieplnej oraz dynamiki reakcji warstwy a tym samym całej przegrody na zmie-

\footnotetext{
1 Autor do korespondencji / corresponding author: Anna Wieprzkowicz, Politechnika Łódzka, Katedra Inżynierii Środowiska, ul. Wólczańska 213, 90-924 Łódź; tel. 4263139 20; anna.wieprzkowicz@p.lodz.pl

2 Dariusz Heim, Politechnika Łódzka, Katedra Inżynierii Środowiska, ul. Wólczańska 213, 90-924 Łódź; tel. 4263139 20; dariusz.heim@p.lodz.pl
} 
niające się warunki brzegowe. Nowo projektowane fasady budynków powinny nie tylko ograniczać straty ciepła ale również w efektywny sposób wykorzystywać zyski ciepła, w ciągu całego roku. Zdolność do magazynowania ciepła i stabilizacji termicznej przegród determinowana jest masą termiczną materiałów, a zatem zdolnością akumulacji ciepła, zarówno jawnego i utajonego.

Konieczność uwzględnienia masy termicznej ściany w ocenie jej efektywności energetycznej została zidentyfikowana i opisana w literaturze za pomocą współczynników charakteryzujących rozkład oporności cieplnej i masy termicznej w przegrodach wielowarstwowych [1]. Kolejnym parametrem, pozwalającym ocenić dane rozwiązanie konstrukcyjne z uwzględnieniem zarówno pojemności jak i przewodności cieplnej, jest współczynnik tłumienia temperatury [2]. Wykorzystując ten parametr, możliwe jest określenie wpływu różnych konfiguracji materiałów izolacyjnych i konstrukcyjnych na warunki termiczne wewnątrz budynku [3, 4]. Współczynnik tłumienia jest obliczany jako stosunek dobowych amplitud wahan temperatury wewnętrznej i zewnętrznej. Wartość ta odzwierciedla zdolność przegrody do wytłumiania wpływu zmieniających się warunków środowiska zewnętrznego oraz stabilizacji temperatury przegrody. Wpływ właściwości fizycznych materiałów oraz absorpcyjności promieniowania słonecznego zewnętrznej powierzchni przegrody na wartość współczynnika tłumienia został opisana w literaturze [5, 6]. Wartość współczynnika tłumienia może być wyznaczona dla rzeczywistych warunków klimatycznych [7] lub uśrednionych sinusoidalnych przebiegów zmian temperatury.

Ocena dynamicznej charakterystyki cieplnej ścian zewnętrznych modyfikowanych Materiałami Fazowo Zmiennymi (MFZ), ze względu na zmieniające się wraz z temperaturą materiału właściwości cieplne, nie może być przeprowadzona bezpośrednio wykorzystując współczynnik tłumienia [8]. Charakterystyka termiczna MFZ zależy od szybkości akumulacji i oddawania ciepła, stanu skupienia oraz zakresu wahań temperatury. Niemniej jednak, współczynnik tłumienia obliczany w zmodyfikowany sposób był wykorzystywany do oceny efektywności zastosowania MFZ w przegrodach transparentnych [9] oraz pełnych [10].

Celem podjętej pracy jest wyznaczenie stabilności termicznej komponentu izolacyjnego modyfikowanego warstwą MFZ. Analiza została przeprowadzona w układzie niestacjonarnym na podstawie rozkładu temperatury w przekroju ściany oraz efektywności akumulacji ciepła utajonego. Zaprezentowane zostały wyniki obliczeń przeprowadzonych dla dwóch wprowadzonych przez autorów, zmodyfikowanych współczynników tłumienia, pozwalających w pełni opisać efekt zastosowania warstwy MFZ na stabilizację termiczną przegrody zewnętrznej.

\section{Opis analizowanego przypadku}

Przedstawiona analiza dotyczy badania dynamicznej charakterystyki cieplnej ściany zewnętrznej. Dlatego też, model budynku poddany analizie numerycznej został ograniczony do jednej strefy (rys. 1). Założono, że jedna ze ścian, 


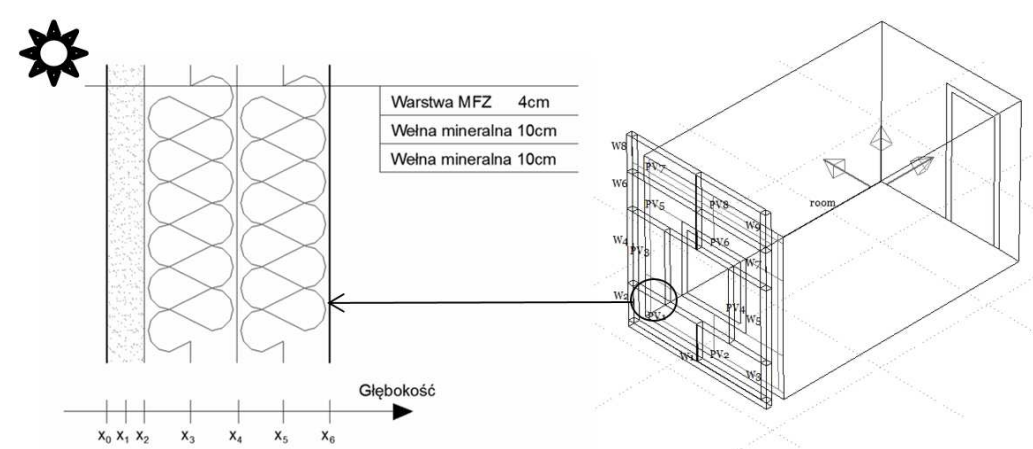

Rys. 1. Schematyczny widok analizowanego pomieszczenia oraz konstrukcji ściany zewnętrznej

Fig. 1. Schematic view of analysed room and wall construction

zwrócona na zachód, będzie pełnić funkcję ściany zewnętrznej, natomiast pozostałe przegrody przyjęto jako wewnętrzne i założono identyczne warunki brzegowe dla wymiany ciepła po obu stronach przegrody. Aby ograniczyć wpływ przegród wewnętrznych na parametry cieplne pomieszczenia przyjęto ich dodatkową izolację.

Analizowana ściana zewnętrzna jest wykonana w konstrukcji lekkiej, z wełny mineralnej oraz warstwy kompozytu zawierającej wosk parafinowy. Właściwości przyjętych do analizy materiałów podano w tabeli 1 . Wartości przewodności cieplnej i gęstości, mające największy wpływ na charakterystykę cieplną warstwy, zostały przyjęte na podstawie wyników badań eksperymentalnych.

Tabela 1. Właściwości materiałów użyte w symulacji

Table 1. Material properties used in simulation

\begin{tabular}{|c|c|c|c|c|c|}
\hline Materiał & $\begin{array}{c}\text { Grubość } \\
{[\mathbf{m}]}\end{array}$ & \multicolumn{2}{|c|}{$\begin{array}{c}\text { Przewodność } \\
\text { cieplna } \\
{[\mathbf{W} / \mathbf{m} \cdot \mathbf{K}]}\end{array}$} & \multirow{2}{*}{$\begin{array}{c}\text { Gęstość } \\
{[\mathbf{k g} / \mathbf{m} 3]}\end{array}$} & $\begin{array}{c}\text { Ciepło } \\
\text { właściwe } \\
{[\mathbf{k J} / \mathbf{k g} \cdot \mathbf{K}]}\end{array}$ \\
\hline \multirow{2}{*}{$\begin{array}{c}\text { Komponent } \\
\text { MFZ }\end{array}$} & 0,04 & c. stałe & ciecz & \multirow{2}{*}{467} & 2000 \\
\cline { 2 - 4 } & 0,16 & 0,13 & 467 & 750 \\
\hline Wełna miner. & 0,20 & \multicolumn{2}{|c|}{0,034} & 110 & 2000 \\
\hline
\end{tabular}

Celem analizy jest ocena stabilności termicznej ściany zewnętrznej modyfikowanej MFZ, w okresie charakteryzującym się niską temperaturą zewnętrzną i wysokim natężeniem promieniowania słonecznego. MFZ wykazuje zdolność magazynowania ciepła utajonego w określonym zakresie temperatur. Problem doboru materiału odpowiadającego danemu zakresowi zmian warunków środowiska zewnętrznego był przedmiotem wcześniejszych badań autorów [11]. Na tej podstawie, na potrzeby poniższej analizy wybrano materiał wykazujący się najwyższą zdolnością akumulacji ciepła utajonego w zakresie od $7^{\circ} \mathrm{C}$ do $9^{\circ} \mathrm{C}$ (rys. 2). 
Symulacje zostały przeprowadzone dla Typowego Roku Meteorologicznego, dla danych klimatycznych miasta Łodzi. W celu przeprowadzenia dokładnej i kompleksowej analizy, przedstawiono wyniki dla wybranego tygodnia zimy, charakteryzującego się znacznymi dobowymi wahaniami temperatury oraz dużym natężeniem promieniowania słonecznego (rys. 3).

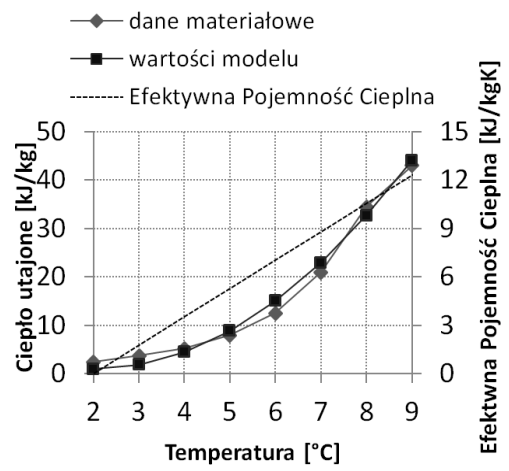

Rys. 2. Zależność pomiędzy wartością ciepła utajonego w funkcji temperatury oraz odpowiadające jej wartości użyte w modelu teoretycznym

Fig. 2. Values of apparent heat capacity used in simulation and corresponding values of modelled latent heat compared to latent heat of real material

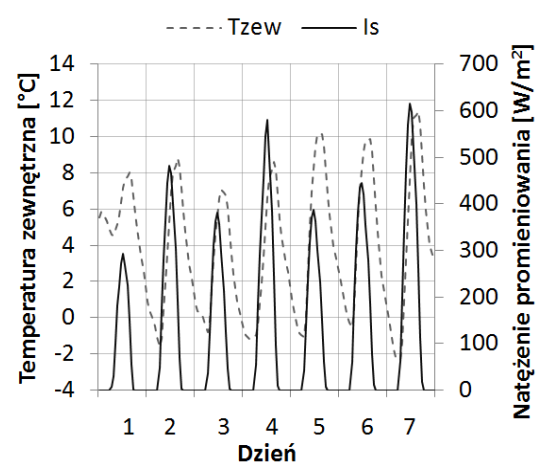

Rys. 3. Historia zmian temperatury zewnętrznej oraz natężenia promieniowania słonecznego $\mathrm{w}$ analizowanym okresie

Fig. 3. History of external temperature and solar irradiance during analysed period

\section{Metodyka}

Analiza została wykonana na podstawie wyników symulacji uzyskanych za pomocą programu ESP-r. Dynamiczny model obliczeniowy zaimplementowany w programie został opisany m.in. w pracach $[12,13]$. Ilość zakumulowanego ciepła utajonego, w zakresie temperatur przemiany fazowej, została wyznaczona metodą Efektywnej Pojemności Cieplnej (ang. Effective Heat Capacity). Równania różniczkowe przewodzenia ciepła są dyskretyzowane dla każdej skończonej objętości modelowanego pomieszczenia, reprezentowanej przez węzeł o parametrach skupionych. Oznacza to, że dla każdej warstwy przegrody przypisane zostały trzy węzły, z których dwa znajdują się na powierzchniach brzegowych i jeden w środku danej warstwy. W celu zwiększenia dokładności modelu i uzyskanych wyników, warstwa izolacji została podzielona na dwie części. Pozwoliło to na uzyskanie wartości temperatury w siedmiu charakterystycznych punktach w przekroju ściany $\left(\mathrm{x}_{0}, \mathrm{x}_{1}, \ldots, \mathrm{x}_{6}\right)$.

Efekt akumulacji ciepła utajonego został opisany poprzez zaproponowane przez autorów dwa parametry bazujące na współczynniku tłumienia. Oba z nich 
obliczane są na podstawie zmieniających się w czasie rozkładów temperatury w przekroju poprzecznym ściany. Na potrzeby analizy porównawczej wprowadzono dodatkowo przypadek referencyjny o identycznej konstrukcji, ale nie wykazujący zdolności akumulacji ciepła utajonego.

Pierwszym z wprowadzonych parametrów jest Zmodyfikowany Współczynnik Tłumienia (ZWT), opisujący tłumienie wahań temperatury na zewnętrznej powierzchni ściany. Obliczany jest jako procent zmniejszenia amplitudy temperatury przez warstwę zewnętrzną ściany w stosunku do amplitudy temperatury na powierzchni zewnętrznej:

$$
Z W T=\frac{\Delta T\left(x_{0}\right)-\Delta T\left(x_{2}\right)}{\Delta T\left(x_{0}\right)} \cdot 100[\%]
$$

gdzie: $\Delta T\left(x_{i}\right)$ - dobowa amplituda temperatur na danej głębokości przegrody.

Wartość podstawowego współczynnika tłumienia obliczana jest na podstawie temperatury zewnętrznej, zakładając pierwszy rodzaj warunków brzegowych. Wartość ZWT obliczana jest biorąc pod uwagę rzeczywiste warunki klimatyczne, w tym również zmienne w czasie natężenie promieniowania słonecznego. Na podstawie wzoru 1, można przyjąć, że im wyższa wartość ZWT, tym wyższą zdolność do stabilizacji temperatury wykazuje analizowana warstwa zewnętrzna ściany. Wartość tego współczynnika obliczono dla każdego dnia analizy, dla przypadku przegrody modyfikowanej MFZ oraz referencyjnego.

Drugim współczynnikiem zaproponowanym przez autorów jest Zmodyfikowany Względny Współczynnik Tłumienia (ZWWT), oceniający efekt zastosowanego MFZ w stosunku do efektu uzyskanego w przypadku referencyjnym. Parametr ZWWT został obliczony dla siedmiu charakterystycznych punktów w przekroju poprzecznym przegrody, pozwalając na ocenę efektu tłumienia temperatury na głębokości ściany:

$$
Z W W T=\frac{\Delta T_{r e f}\left(x_{i}\right)-\Delta T_{M F Z}\left(x_{i}\right)}{\Delta T_{r e f}\left(x_{i}\right)} \cdot 100[\%], i=\{0,1, \ldots, 6\}
$$

\section{Analiza wyników}

Wartości dwóch zaproponowanych parametrów ZWT i ZWWT wyznaczone zostały na podstawie zmiennych w czasie rozkładów temperatury w przekroju poprzecznym ściany (rys. 4). Na podstawie tak przedstawionych wyników można zauważyć, że zastosowanie warstwy MFZ od strony zewnętrznej przyczynia się: do stabilizacji temperatury powierzchni, utrzymania temperatury w warstwie MFZ w zakresie temperatur przemiany fazowej, zmniejszenia wahań temperatury w warstwie izolacji. Ponadto, zauważyć można że największe różnice pomiędzy wynikami otrzymanymi dla dwóch analizowanych przypadków zostały uzyskane w okresie największego natężenia promieniowania słonecznego. Potwier- 

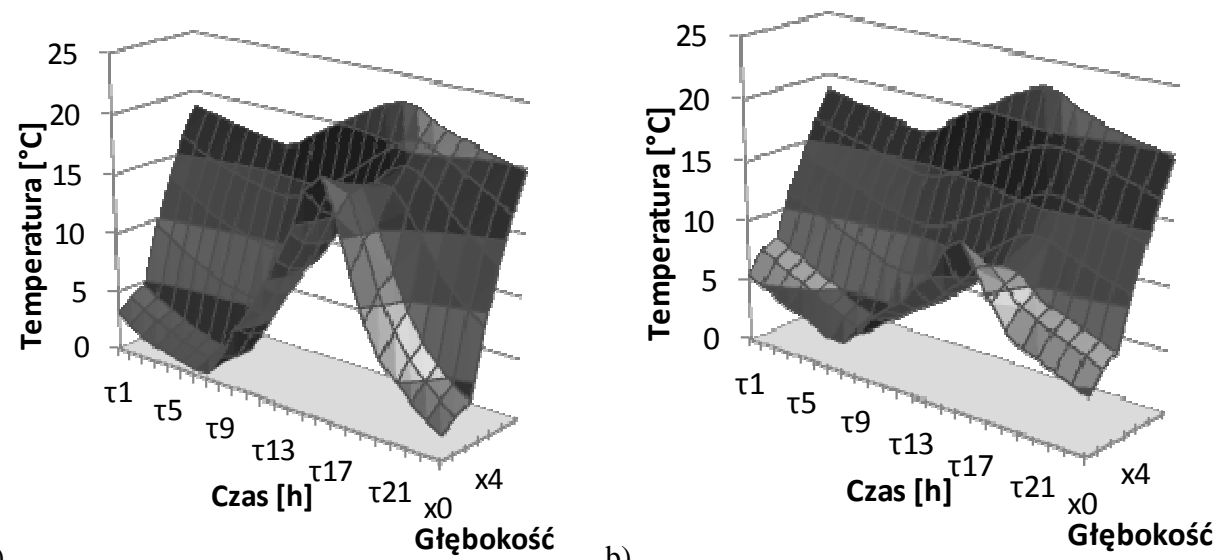

b)

Rys. 4. Rozkład temperatury w przekroju poprzecznym ściany dla przypadku: a) referencyjnego, b) modyfikowanego MFZ

Fig. 4. The temperature distribution in the cross section of the wall for case: a) without PCM, b) with PCM

dza to konieczność kompleksowego uwzględnienia warunków pogodowych, a nie tylko temperatury zewnętrznej jak w przypadku standardowego współczynnika tłumienia.

Uzyskane wartości ZWT pozwalają na ilościowe określenie uzyskanego efektu akumulacji ciepła utajonego. Wyniki przedstawione na rysunku 5 wskazują, że zwiększenie pojemności cieplnej zewnętrznej warstwy przegrody - warstwy w której występują duże wahania temperatury - pozwala na skuteczne zmniejszenie wpływu intensywnie zmieniających się warunków zewnętrznych na temperaturę przegrody. Wartości ZWT otrzymane dla przypadku referencyjnego zmieniają się w przedziale od $9 \%$ do $14 \%$, podczas gdy dla przypadku modyfikowanego MFZ od $17 \%$ do $34 \%$.

Wyniki przedstawione na rysunku 6 pokazują różnicę pomiędzy występującą amplitudą temperatur dobowych w analizowanych dwóch przypadkach: modyfikowanym MFZ i referencyjnym, na określonej głębokości w ścianie. Można zauważyć, że największy efekt akumulacji ciepła utajonego dla większości dni, analizowanego okresu czasu, występuje w warstwie MFZ. Niemniej jednak, wartości są znaczące również na większych głębokościach ściany, w warstwie izolacji. Potwierdza to tezę, że zastosowanie MFZ na zewnętrznej powierzchni ściany ma wpływ na charakterystykę termiczną całej przegrody. 


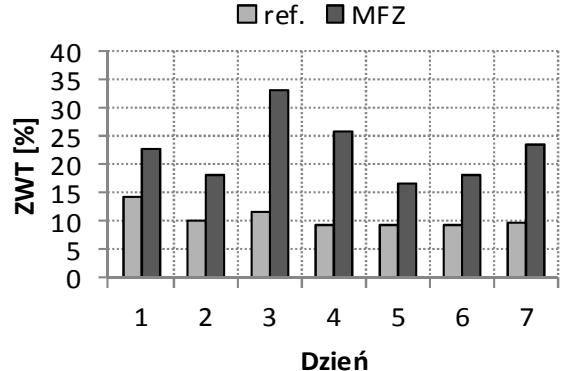

Rys. 5. Uzyskane wartości ZWT w analizowanym okresie czasu

Fig. 5. Values of ZWT for analysed period of time

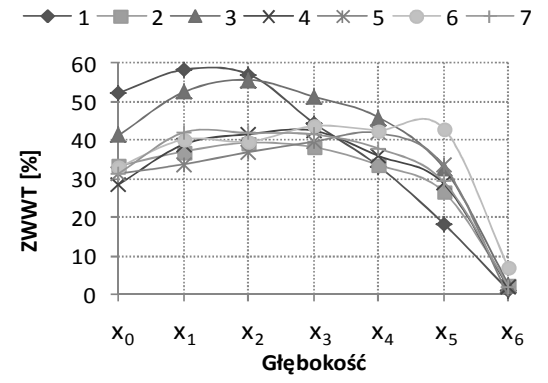

Rys. 6. Uzyskane wartości ZWWT w analizowanym okresie czasu

Fig. 6. Values of ZWWT for analysed period of time

\section{Podsumowanie}

W artykule zaproponowane zostały dwa współczynniki określające tłumienie amplitudy wahań temperatur przez przegrody modyfikowane warstwą MFZ, uwzględniające kompleksowo warunki klimatu zewnętrznego takie jak: temperatura zewnętrzna, natężenie promieniowania słonecznego, kierunek i prędkość wiatru. Wyznaczenie wartości powyższych parametrów pozwoliło na ilościowe określenie możliwości stabilizacji temperatury przegrody poprzez zastosowanie MFZ. Na podstawie pokazanych wyników można stwierdzić, że wprowadzenie dodatkowej warstwy MFZ przyczynia się do stabilizacji temperatury w zakresie temperatur przemiany fazowej w warstwie MFZ, jak również do zmniejszenia wahań temperatury w całej przegrodzie.

\section{Literatura}

[1] Kossecka E., Kosny J.: Influence of insulation configuration on heating and cooling loads in a continuously used building. Energy and Buildings, vol. 34, 2002, pp. 321-331.

[2] Asan H., Sancaktar Y.S.: Effects of Wall's thermophysical properties on time lag and decrement factor. Energy and Buildings, vol. 28, 1998, pp. 159-166.

[3] Al-Sanea S.A., Zedan M.F., Al-Hussain S.N.: Effect of thermal mass on performance of insulated building walls and the concept of energy savings potential. Applied Energy, vol. 89, 2012, pp. 430-442.

[4] Mavromatidis L.E., Mankibi M., Michel P., Santamouris M.: Numerical estimation of time lags and decrement factors for wall complexes including Multilayer Thermal Insulation, in two different climatic zones. Applied Energy, vol. 92, 2012, pp. 480-491.

[5] Asan H.: Numerical computation of time lags and decrement factors for different building materials. Building and Environment, vol. 41, 2006, pp. 615-620.

[6] Kontoleon K.J., Eumorfopoulou E.A.: The influence of wall orientation and exterior surface solar absorptivity on time lag and decrement factor in the Greek region. Renewable Energy, vol. 33, 2008, pp. 1652-1664. 
[7] Larsen S.F., Filippín C., Lesino G.: Thermal behavior of building walls in summer: comparison of available analytical methods and experimental results for a case study. Building Simulation, vol. 2, 2009, pp. 3-18.

[8] Zhang Y., Lin K., Jiang Y., Zhou G.: Thermal storage and nonlinear heat-transfer characteristics of PCM wallboard. Energy and Buildings, vol. 40, 2008, pp. 1771-1779 .

[9] Zhong K., Li S., Sun G., Li S., Zhang X.: Simulation study on dynamic heat transfer performance of PCM-filled glass window with different thermophysical parameters of phase change materia. Energy and Buildings, vol. 106, 2015, pp. 87-95.

[10] Mandilaras I., Stamatiadou M., Katsourinis D., Zannis G., Founti M.: Experimental thermal characterization of a Mediterranean residential building with PCM gypsum board walls. Building and Environment, vol. 61, 2013, pp. 93-103.

[11] Heim D., Wieprzkowicz A.: Positioning of an isothermal heat storage layer in a building wall exposed to the external environment. Journal of Building Physic Simulation, styczeń 2016.

[12] Clarke A.J.: Energy Simulation in Building Design, 2nd ed., ButterworthHeinemann, Oxford 2001.

[13] Heim D., Clarke J.A.: Numerical modeling and thermal simulation of PCMgypsum composite with ESP-r. Energy and Buildings, vol. 36, 2004, pp. 795-805.

\section{DECREMENT FACTOR OF THERMAL INSULATION MODIFIED BY PHASE CHANGE MATERIAL}

\section{S u m m a r y}

The aim of presented study is to determine the thermal stability of the modified insulation layer by PCM. The analysis was carried out using results obtained by dynamic model of heat transfer based on the temperature distribution in the wall section. The authors proposed two modified decrement factors (MDF and MRDF), which can be used to determine the effect of the PCM layer application to thermal stabilization of the outer layer of external partition. The coefficients was determined based on the results of simulation analysis curried out for Polish climatic conditions. Comparison of the results obtained for the reference and the modified external wall showed the differences in the values of MDF from a few to several percent depending on the analyzed period of time.

Keywords: thermal dynamic, computer simulation, externall wall, heating season, zero-energy building

Przestano do redakcji: 29.05.2017 $r$.

Przyjęto do druku: $30.06 .2017 \mathrm{r}$. 